extend to 15 countries in the English-speaking Caribbean. Support in the form of finance or accommodation is provided by the World Health Organization (Pan American Health Organization), F.A.O., U.N.I.C.E.F., the Williams Waterman Program, the University of the West Indies, and the Governments of Jamaica and Trinidad and Tobago. The director is Dr. D. B. Jelliffe, a leading authority on the nutritional aspects of paediatrics. The professional staff, international in character, is relatively small, consisting of about nine members with experience in nutrition and related fields. A budget of $\$ 419,500$ for five years covers staff, consultants, field investigations, travel, equipment and supplies, and the cost of a "training course in community nutrition" held every second year for appropriate people from the area. The institute follows an interdisciplinary approach in all its activities, including research. An entire number of the fournal of Tropical Pediatrics ${ }^{1}$ has been devoted to its programme and contributions from its staff.

Protein-calorie malnutrition, reflected in high mortality in infants and young children, was until recently widely prevalent in the Caribbean. Pioneer research on the problem has been done by J. C. Waterlow and his colleagues in Jamaica. ${ }^{2}$ In many territories it is now coming under control, with the infant mortality rate down to $40+$ per 1,000 live births. The rate on the slave estates probably used to be over 500 , and high rates persisted after emancipation. The conquest of protein-calorie malnutrition will be hastened by the institute's programme. A relic of slavery which affects maternal and child welfare is the matriarchal structure of society, with diminished paternal responsibility.

Another major problem for the institute to study is the dependence of the Caribbean on food imports, which is increasing year by year. This, again, derives from the monoculture of sugar in earlier days.

The Caribbean Food and Nutrition Institute has much interesting and important work to do in an area where results are readily visible and easily recorded. Progress is reported in a lively bi-monthly journal called Cajanus, after a legume (the pigeon pea) which is a potential source of needed protein.

\section{Prostatic Syncope}

Though rectal examination has sometimes been thought to carry a risk for patients with heart disease, D. L. Earnest and G. F. Fletcher ${ }^{12}$ showed it to be safe for those with acute myocardial infarction, and their rectal findings justified the need for the examination. But since their report a number of adverse reactions to prostatic palpation have been described. R. H. Bilbro ${ }^{3}$ has recorded eight episodes of either frank syncope or faintness during 2,500 prostatic examinations. In one patient the syncope was accompanied by a brief generalized seizure. The patients turned pale and had a bradycardia of 48 beats per minute or less. As these patients showed a precipitous loss of consciousness if they were not placed supine it must be assumed they were not lying down when

\footnotetext{
1 Earnest, D. L., and Fletcher, G. F., New England fournal of Medicine, $1969,281,238$

2 British Medical fournal, 1969, 4, 319.

3 Bilbro, R. H., New England Fournal of Medicine, 1970, 282, 167.

- Poleshuck, V. A., New England fournal of Medicine, 1970, 282, 632.
}

rectal examination was carried out. V. A. Poleshuck ${ }^{4}$ describes $^{2}$ the collapse of a 30-year-old man after examination of the prostate. After sustaining a head wound while falling, he had a mild seizure and subsequently became apnoeic and pulseless. A blow to the anterior chest produced a carotid pulse with a bradycardia of 46 beats per minute. The patient regained consciousness after three minutes and recovered uneventfully. His father and paternal uncle had suffered syncopal attacks after rectal examination. Again, it seems that this patient was not lying down during the examination.

There is the occasional patient who is so dyspnoeic on lying down that rectal examination is more practical if he stands and leans forwards. For the vast majority, however, maximal information can be attained with the patient placed in the left lateral position with the buttocks at the edge of the bed and the knees well drawn up, though some doctors may prefer to have the patient in the dorsal position. The patient should be instructed to breathe freely through the mouth, as this will relax the abdominal muscles for bimanual palpation and avoid a Valsalva manoeuvre. The finger should be well lubricated and introduced slowly. Both transrectal needle biopsy of the prostate and prostatic massage to obtain prostatic secretions are perfectly feasible in this position. After either of these procedures, or if the rectal examination causes more discomfort than usual, the patient should be allowed to remain horizontal for a few minutes and then get up slowly. In this way syncope will be avoided and rectal examination will continue to enjoy its safe and valuable reputation.

\section{Protean Symptomatology of Myxoedema}

One of the many fascinations of clinical endocrinology is the variety of ways in which its clinical syndromes present. Despite all the achievements of diagnostic science there is still the need for some astute clinician to suspect the disease before the appropriate battery of confirmatory tests can be fired off. In future the choice of them may be eased by computer analysis of symptoms and signs, but at present a high index of diagnostic suspicion is more economical and more exact. These considerations apply with special force to the recognition of disorders of parathyroid and thyroid function and in particular to the early diagnosis of hypothyroidism.

Delays in the diagnosis of thyroid failure most often occur when the onset is gradual and protracted or when one organ or system of the body reacts out of proportion to the others. This illustrates the old principle that each patient is an individual with his own peculiar diathesis and not a predictable machine. Moreover, in this age of increasing specialization patients with undiagnosed hypothyroidism may reach the wrong specialist owing to their having presented with the symptoms appropriate to that particular specialty. They bypass the general physician or endocrinologist, who might have been able to recognize more promptly the underlying disorder.

The E.N.T. surgeon, when faced with a patient with a croaky voice, may diagnose hypothyroidism only after a laryngeal biopsy has disclosed myxoedematous tissue; or the

\footnotetext{
1 Golding, D. N., Annals of the Rheumatic Diseases, 1970, 29, 10.

2 Fessel, W. J., Annals of the Rheumatic Diseases, 1968, 27, 590.

${ }^{3}$ Fincham, R. W., and Cape, C. A., Archives of Neurology, 1968, 19, 464.
} 